LEITURA - ESPAÇOS HÍBRIDOS: n. 28, n.29, p.227-240.

\title{
LITERATURA E PSICOLOGIA: UM DIÁLOGO INTERARQUETÍPICO
}

\section{Edilma Acioli Bomfim ${ }^{(*)}$}

Resumo: Este artigo propõe uma leitura de duas conferências proferidas por C. G. Jung, em 1922, a respeito da possibilidade de a crítica literária servir-se dos argumentos por ele defendidos no seu estudo sobre arquétipos. Para o autor, a arte, de uma maneira geral, é uma atividade humana de caráter psicológico e, assim sendo, pode ser analisada segundo um prisma também psicológico.

Palavras-chave: Arquétipo; processo criador; imagem primordial; metáfora

A relação interdisciplinar entre Psicologia e Literatura de que a crítica literária, de um modo geral, se vem servindo com muita propriedade, suscita, no mínimo, duas questões pertinentes: a primeira se refere ao papel da crítica literária e da psicologia na leitura do texto artístico; a segunda questiona até que ponto uma pode servir-se da outra para apreender, nos seus campos específicos, o conhecimento humano subjacente à obra de arte poética.

Reconhecemos que a psicologia e a literatura têm produzido diálogos profícuos e iluminados, já que são dois territórios que configuram uma interface de interlocução possível, que é a expressão do desejo em suas várias formas discursivas.

Uma vez que o estudo do mito sob uma perspectiva psicológica está fundamentalmente associado ao nome de C. G. Jung, cuja obra está impregnada de sentido mítico, buscamos, na concepção mitológica/arquetípica desse estudioso da consciência moderna, elementos que ajudassem a esclarecer a relação existente entre o criador, o objeto criado e a leitura, a qual se pode empreender entre esses elementos do processo narrativo e o próprio ato de criar.

A esse respeito, embasamo-nos em uma conferência - ponto de partida desse trabalho crítico - proferida por Jung, em maio de

(") Professora do Programa de Pós-Graduação em Letras e Linguística da Ufal.; doutora em Literatura Brasileira (Ufal). 
1922, na Sociedade de Língua e Literatura Alemãs, em que ele trata da "Relação da Psicologia Analítica com a obra de arte poética". Consideramos muito pertinentes as colocações de Jung nesse texto, no sentido de que deixa claro que a Psicologia Analítica não se propõe a opinar sobre o valor estético da obra de arte, pois centra suas observações no processo de atividade criadora e no estudo psicológico da estrutura da produção artística. Assim, a grande contribuição de Jung para os estudos literários é a decifração ou o reconhecimento das imagens simbólicas arquetípicas que se materializam na produção artística, trazendo luz para as significações discursivas.

Assim, a hipótese da nossa pesquisa - Psicologia Analítica e texto literário - se assenta na idéia de Jung, que vê nos arquétipos a gênese do processo criador e, dessa forma, entendemos que a estrutura psíquica das personagens construídas ficcionalmente revela imagens ancestrais, herdadas e reelaboradas, à medida que a obra de arte atualiza essa ancestralidade psíquica.

Na citada conferência "Relação da Psicologia Analítica com a obra de arte poética", Jung partiu de um pressuposto a respeito da atividade artística que consideramos básico para o entendimento da leitura do texto literário à luz da crítica psicológica. Para ele, a arte, em sua manifestação, é uma atividade humana de base psicológica e, nesse sentido, pode ser submetida a considerações de cunho psicológico. Sendo, pois, oriunda de causas psicológicas, é, pois, objeto da Psicologia.

Verificamos, no entanto, que essa mesma constatação estabelece alguns limites a esse olhar crítico sobre o texto poético:

Apenas aquele aspecto da arte que existe no processo de criação artística pode ser objeto da Psicologia, não aquele que constitui o próprio ser da arte. Nessa segunda parte, ou seja, a pergunta sobre o que é a arte em si, não pode ser objeto de considerações psicológicas, mas apenas estético-artísticas (JUNG, 1985, p.54).

Verificamos que, para Jung, a arte possui peculiaridades que the são próprias e que só podem ser explicadas por si mesmas: de

JUNG. C.G. "Relação da psicologia analítica com a obra de arte poélica." In: O espirito na arte e na ciência. Tradução Maria de Moraes Barros. Petrópolis: Vozes, 1985. 
outro modo, corre-se o risco de violar a própria natureza do fenômeno artístico.

Outro dado importante citado por Jung nessa conferência é aquele que se refere à idéia de que, na análise de um texto poético não devemos propor "falar do poeta como pessoa, mas do processo criador" (p.62). Julgamos isso um avanço considerável da crítica junguiana, um deslocamento da pessoalidade para a obra, priorizando a criação no que ela tem de mais singular, evitando violar a natureza do fenômeno artístico; é necessário, então, procurarmos o "sentido da obra" sem que nos prendamos obrigatoriamente aos dados biográficos do artista.

Entendemos que quem fala na narrativa não é quem escreve e quem narra, não é quem é. Assim, o autor pertence ao mundo da realidade histórica; o narrador, a um universo imaginário. Entre ambos encontramos relações, mas não identidades. É, pois, de forma relacional que podemos vincular, em alguns momentos, a vida de determinado autor ao seu universo imagístico, vendo nessa relação um sinal do caráter "estranho" e perturbador da construção artística.

Dessa forma, tendo o cuidado de ressaltar a importância da obra de arte independente do Autor criador, Jung apresenta, em uma segunda conferência, que denominou de "Psicologia e poesia", 2 dois processos diferentes de criação por meio dos quais toda obra de arte há de se manifestar: os chamados "modo psicológico e modo visionário" de criar. O primeiro está estreitamente ligado às experiências do cotidiano, portanto, vinculado ao consciente pessoal do produtor, como as paixões, alegrias, dores, os sofrimentos, o cotidiano, enfim, as tragédias comuns à humanidade e que, dessa maneira, são facilmente detectadas pela crítica especializada ou pelo leitor comum. O segundo modo de produção artística, por sua vez, está visceralmente ligado aos elementos anímicos, portanto ao inconsciente do Autor, sendo, por sua vez, de mais difícil apreensão por parte da crítica e do leitor; além disso, a criação visionária teria uma relação necessária com a experiência originária arquetípica do artista, algo que não tem correspondência no cotidiano, constituindo a "expressão de uma essencialidade desconhecida" (p.77). Reconhece ainda Jung que a forma visionária de produção "rasga de alto a baixo a

2 JUNG, C. G. "Psicologia e poesia". In: O espirito na arte e na ciência. Op. cit., 1985. 
cortina na qual estão pintadas as imagens cósmicas, permitindo uma visão das profundezas incompreensíveis daquilo que ainda não se formou" (p.79). Daí a estranheza que causam perturbando profundamente o leitor, pois os seres ficcionais se apresentam misteriosos vivendo dentro de uma atmosfera ainda mais misteriosa.

Dante Moreira Leite, falando da impressão perturbadora e estranha causada por um texto visionário, diz que diante dessa escritura "somos obrigados a procurar um sentido, pois diante dela nos sentimos confusos", uma vez que o que se acha simbolicamente representado "é o inconsciente coletivo, isto é, determinada disposição formada pelas experiências ancestrais, e a partir do qual evolui a consciência"'(p.128-9). ${ }^{3}$

Jung reconhece que há determinadas obras que caminham paralelas à vida do autor e, nesses casos, o conhecimento prévio pode facilitar a compreensão do fenômeno artístico, conforme podemos perceber neste seu discurso:

O condicionamento prévio só interessa na medida em que facilitar a melhor compreensão do sentido. A causalidade pessoal tem tanto ou tão pouco a ver com a obra de arte. quanto o solo tem a ver com a planta que dele brota. Certamente poderemos conhecer determinadas peculiaridades da planta, quando conhecermos as condições de seu habitat (p. 60. Grifo nosso).

Essa fala de Jung apresenta duas advertências: a primeira é que a obra e o artista não podem ser vistos como um doente necessitado de um diagnóstico, visando a uma possível cura, não sendo a causa do fenômeno artístico que se procura. A compreensão dessa "causalidade pessoal" é dispensável quando se trata da obra de arte, visto que ela não é um ser humano (na qual se pode tentar encontrar as "causas" para investigar alguns fatores psicossomáticos), mas algo "suprapessoal", representação

3 LEITE, Dante Moreira. Psicologia e literatura. São Paulo: Nacional. 1977. Moreira Leite apresenta dois textos literários para exemplificar os modos de criação, denominados psicológico e visionário de criar: no primeiro caso, cita o romance de Cyro dos Anjos O amanuense Belmiro e no segundo, "A terceira margem do rio" de Guimarães Rosa. Da mesma coletânea - Primeiras estórias - de Guimarães Rosa, citamos ainda o conto "Soroco, sua mãe, sua filha" que mantém o mesmo clima de estranheza e perturbação próprios da literatura visionária. 
ou (re)leituras de imagens e mitos que povoam o inconsciente e/ou consciente artístico. Jung diz ainda que uma das peculiaridades da obra de arte é poder se libertar de tudo que seja pessoal, elevando-se para além do efêmero, do apenas pessoal. Por outro lado, essa sua mesma fala dá a segunda possibilidade de leitura quando reconhece que a base em que se assenta "a planta" é um dado de grande importância para o seu florescimento. Com isso, não deixa de reiterar que o alicerce psíquico em que o indivíduo se apóia é um dado significativo para o estudo da sua obra.

Entendemos que a sua preocupação é de que não devemos tratar a criação artística como uma manifestação neurótica ou psicótica, correndo o risco de desviar o interesse da obra literária, o seu mundo ficcional - personagens, enredos, tempos, espaços e efabulações - para a história pessoal do autor. Por exemplo: se um ser ficcional, na narrativa, apresenta uma relação neurótica, conflituosa, com o paipersonagem, Jung recomenda cautela para que essa relação não seja analisada como um dado da história de vida do autor, pois, com esse procedimento, a representação poética passaria a ser vista de forma reducionista, "sempre" e "tão-somente" como um texto auto-referente, confessional ou autobiográfico.

Dentro desse raciocínio, Jung é enfático ao afirmar que "quando uma obra de arte é interpretada da mesma forma como uma neurose, de duas uma: ou a obra de arte é uma neurose ou a neurose é uma obra de arte"(1985, p.56). Com esse trocadilho, Jung abomina que demos ao poeta e a sua obra o mesmo encaminhamento que um psicólogo dá ao psicótico em seu processo de tratamento. Para a Psicologia Analítica, o fato a ser observado no universo poético é a "criação artística" ou, no dizer de Jung, o que se deve procurar entender é o que está por trás do "mistério da criação".

\section{Processo de criação: uma abordagem arquetípica}

Então, chegamos à questão básica da conferência de Jung e também do nosso interesse com relação à análise do texto literário: o que está mesmo por trás do processo criador, fazendo que a obra se preste ao olhar da Psicologia Analítica? Jung afirma que podemos encontrar nos arquétipos a gênese do processo criador; com essa afirmação, ele põe em evidência a existência de um inconsciente coletivo que mergulha suas raízes na vida instintiva, que é o depósito 
constituído por toda a experiência ancestral da humanidade há milhões de anos, constituindo uma espécie de imagem eterna do mundo. Seu campo é muito mais vasto do que o da psique individual e, nesse sentido, os arquétipos dispõem de energias muito mais poderosas, pois sua linguagem utiliza símbolos que são infinitamente ricos, múltiplos e variados. Esses arquétipos correspondem às experiências fundamentais típicas do ser humano desde o começo do mundo; seus motivos são os mesmos em todas as civilizações, e nós os reencontramos em todas as mitologias, nas lendas, nos contos de fadas, nas tradições religiosas e em inúmeras obras de arte, nas suas mais diversas manifestações. Mitos e obras representam, sob uma forma imagística e simbólica, processos psíquicos, correspondendo a certos conteúdos do inconsciente coletivo que reaparecem em cada psique individual.

Os arquétipos são energias psíquicas vitais e, portanto, têm que ser levados a sério. Ao desprezá-los, arriscamo-nos "aos perigos da alma" bem conhecidos na psicologia do primitivo. Para Jung qualquer referência ao arquétipo é sempre perturbadora pois ele

Solta em nós uma voz muito mais poderosa do que a nossa. Quem fala através de imagens primordiais, fala como se tivesse mil vozes; comove e subjuga, elevando simultaneamente aquilo que qualifica de único e efêmero na esfera do contínuo devir, eleva o destino pessoal ao destino da humanidade (1985, p.70).

Tornar esse material acessível a sua própria psique, projetá-lo e integrá-lo ao consciente significa romper a solidão do homem moderno, incorporando-o ao "rio da vida", ajudando-o a tornar-se um
indivíduo total.

E aqui, segundo Jung, cabe uma pergunta essencial: “a que imagem primordial do inconsciente coletivo pode ser reduzida a imagem desenvolvida na obra de arte" (p.70)? E, ainda, onde a arte se encaixa dentro desse processo de projeção do inconsciente como parte da construção psíquica do indivíduo?

Entendemos que o processo criador é uma ativação dessa energia ancestral que se acha concentrada no inconsciente coletivo; quando essa energia primordial é ativada e toma uma forma, temos aí a imagem arquetípica. Não podemos denominar essa imagem de arquétipo, pois o arquétipo é unicamente uma virtualidade ou como 
diz Jung: "O arquétipo é um dinamismo que se faz sentir na numinosidade e no poder de fascinação da imagem arquetípica (p.163).",

Partindo da idéia de que o texto literário é simbólico e/ou metafórico, ele é em si uma representação do imaginário, desenho ou corporificação dessa imagem ancestral que habita o inconsciente do artista. A obra de arte pode ainda ser entendida como uma maneira de estabelecer uma relação com o inconsciente; compreendendo sua linguagem, o texto se configura, então, como uma imagem do arquétipo.

Assim, a respeito da imagem do inconsciente coletivo que se assemelha à imagem representada na obra poética, Jung afirma:

Considerei aqui o caso de uma obra de arte simbólica e cuja origem não deve ser procurada no inconsciente pessoal do autor, mas naquela esfera da mitologia inconsciente cujas imagens primitivas pertencem ao patrimônio comum da humanidade. Foi por isso que denominei essa esfera de inconsciente coletivo (1985, p.68).

Notamos pela citação que Jung faz uma distinção entre o que denominou inconsciente pessoal e inconsciente coletivo, também chamado de inconsciente impessoal ou suprapessoal. Estabelecendo essa distinção que considera significativa na compreensão ou feitura do processo criativo e de construção da individualidade do ser, Jung distingue essas duas camadas do inconsciente, afirmando que 0 inconsciente coletivo se distingue do pessoal por seus caracteres serem totalmente universais e seus conteúdos encontrados em toda parte, época e civilização; já o inconsciente pessoal

contém lembranças perdidas, reprimidas (propositalmente esquecidas), evocações dolorosas, percepções que, por assim dizer, não ultrapassam o limiar da consciência (subliminais), isto é, percepções dos sentidos que por falta de intensidade não atingiram a consciência e conteúdos que ainda não amadureceram para a consciência (p.58). ${ }^{5}$

\footnotetext{
4 JUNG, C. G. A natureza da psique. Tradução Dom Mateus Ramalho Rocha. Petrópolis: Vozes, 1991.

5 JUnG, C. G. Psicologia do inconsciente. Tradução Maria Luiza Appy. Petrópolis: Vozes, 1987.
} 
Em outras palavras, podemos dizer que o inconsciente coletivo representa a camada objetiva da composição psíquica; o inconsciente pessoal, por sua vez, representa a camada subjetiva da mente humana.

As palavras, os temas, as efabulações, um sem número de personagens, os mais diversos tipos de espaços ficcionais (re)inventados no momento criador, as inusitadas metáforas que compõem a essência do texto lírico, o tempo ficcional revertendo a temporalidade cronológica do cotidiano, diálogos, monólogos, solilóquios, enfim, os símbolos e imagens que se sucedem a cada novo texto que se produz são representações atualizadas das imagens antigas e universais da imaginação humana, da energia psíquica latente, herdada e reprogramada à medida que o texto literário se faz enunciação (e não enunciado) dessa imagem primeira. Quando afirmamos ser a obra literária um elemento de enunciação, estamos querendo não perder de vista o caráter estético do texto artístico, o que distingue a arte de outras formas de expressão consideradas nãoartísticas. Jung também reconhece essa autonomia no processo artístico quando, refletindo sobre o "sentido" da arte, diz que "a arte é beleza e nisso ela se realiza e se basta a si mesma"( 1985, p.66).

No processo criador, a energia psíquica faz-se imagem artística, transformando-a em imagem poética amadurecida para a consciência criadora, segundo o critério artístico do produtor. Diz Jung que

Neste caso, o autor submete seu material a ser trabalhado a um tratamento com propósito definido, tirando ou adicionando, enfatizando um efeito, atenuando outro, dando um toque colorido aqui ou acolá, considerando cuidadosamente os efeitos e observando constantemente as leis do belo e do estilo (p.61).

Sabemos que um texto nunca se inicia com uma página em branco. A teoria da intertextualidade já vem há algum tempo propondo essa assertiva. Mikhail Bakhtin, ${ }^{6}$ ao refletir sobre a relação de um texto com outro, vê o discurso literário como o que apresenta múltiplas relações com outros textos ou com outras vozes presentes no discurso.

BAKHTIN, Mikhail. Marxismo e filosofia da linguagem. Tradução Michel Lahud e Yara Frasteschi. 6. ed. São Paulo: Hucitec, 1992. 
Entende o texto como um intercâmbio discursivo, uma tessitura polifônica na qual confluem, metamorfoseiam-se, ratificam-se ou se contestam outras falas, outros discursos e outras vozes.

Dentro desse mesmo raciocínio, Julia Kristeva ${ }^{7}$ afirma que a palavra literária não é um ponto fixo, mas um cruzamento de superfícies textuais, que se "constrói como um mosaico de citações"(p.85).

Assim, aceitando o conceito de texto literário como discurso que, necessariamente, retoma outros, é que entendemos o porquê de a expressão literária realizar-se, envolvendo desde concepções e definições de imagens já cristalizadas, até as novas relações de texturas e metáforas, que vão aparecendo, desaparecendo e voltando a aparecer, para a conformação final da obra.

Esse processo, que lida com fatores conscientes e inconscientes, mentais e sensoriais, provocados e casuais, não é mera variação caprichosa na combinação de elementos que constituem a linguagem deste ou daquele artista; a realização da obra abre sempre a possibilidade de uma ampliação ou (re)leitura dessas inúmeras outras vozes discursivas. Jung lê essas vozes como a comprovação de que "em tais momentos não somos mais indivíduos, mas uma espécie; pois a voz de toda a humanidade ressoa em nós"(1985: p.70).

Nise da Silveira, ao analisar alguns trabalhos artísticos de doentes mentais no seu livro $O$ mundo das Imagens, ${ }^{8}$ reconhece que as imagens arquetípicas constituem os temas míticos que condensam e exprimem as mais intensas experiências da humanidade. Para ela "é aí que estão as raízes da nossa vida psíquica, a fonte de toda a imaginação criadora" (p.86).

Centrada ainda na teoria de Jung, a estudiosa considera que as imagens míticas pertencem à estrutura do inconsciente e são um dado impessoal pelo qual os indivíduos são mais por ele possuídos do que possuem. Na origem, o mito repousa, portanto, sobre uma experiência psíquica individual que corresponde às aspirações coletivas de um povo; a narração dessa experiência será repetida e refinada pelas múltiplas experiências individuais e coletivas. A obra de arte é uma

7 KRISTEVA, Julia. Introdução à semanálise. Tradução Lúcia Helena França Ferraz. São Paulo: Perspectiva, 1974.

8 SILVEIRA, Nise da. O mundo das imagens. São Paulo: Ática, 1992. 
decodificação das imagens simbólicas que tomam forma na escritura, e o escritor extrai seus temas das experiências vividas no percurso da existência humana, elevando-os ao caráter da representação artística e universalizando-os.

\section{Literatura: reconstrução da imagem primordial}

Percebemos, então, assentadas nessas reflexões, que temos no inconsciente um potencial de idéias que clama por uma expressão, já que as possibilidades de concretização das idéias existem a priori:

Idéias inatas não existem; existem possibilidades inatas de idéias que colocam determinados limites também às mais ousadas fantasias, colocam categorias, por assim dizer, à capacidade de fantasiar, colocam certas idéias a priori, cuja existência não se pode afirmar sem a experiência (JUNG, 1985, p.69).

A maneira como essas idéias latentes eclodem ou se projetam não é em si a idéia primordial milenar que vai surgir agora no inconsciente, mas é o "como" essa idéia é agora, no momento, experienciada, entendida e representada metaforicamente na escritura, o que vai constituir o que Jung chama de "processo da criação" ou o que podemos entender como leitura contemporânea dessa imagem originária:

Muitas vezes já nos aconteceu redescobrirmos repentinamente um poeta. Isso ocorre quando nossa evolução consciente já alcançou graus mais elevados. e, a partir deles, o velho poeta nos diz algo de novo. Já existia antes em sua obra, mas era um símbolo escondido que só nos foi permitido ler após uma renovação do espírito da época. Houve necessidade de outros e novos olhos, pois os antigos só poderiam ver o que estavam acostumados a ver (p.65).

Eis a razão por que Gerhart Hauptmann, citado por Jung no momento da sua conferência, afirma: "Poesia significa deixar ressoar atrás das palavras a palavra primordial" (p.68).

HAUPTMANN, Gerhart. Apud JUNG, C. G. Relação da psicologia analítica com a obra de arte poética. 
Como essa imagem primordial, o arquétipo é uma figura como exemplos podemos citar a mãe, a santa, o demônio, o louco que aparece, desaparece e reaparece no transcurso da história da humanidade, sempre que a imaginação criativa necessitar da sua expressão livre. Constituem-se, antes de tudo, em figuras mitológicas, ou como diz Jung textualmente: "são de certo modo, o resultado formado por inúmeras experiências típicas de toda uma genealogia" ou, ainda, "são os resíduos psíquicos de inúmeras vivências do mesmo tipo" (p.69).

Jung apresenta algumas considerações com relação ao que ele denomina arquétipo e o que chama de imagem arquetípica. Alerta que não devemos confundir as representações arquetípicas que são transmitidas pelo inconsciente com o arquétipo em si. Diz que:

Essas representações são estruturas amplamente variadas que nos remetem para uma forma básica irrepresentável, que se caracteriza por certos elementos formais e determinados significados fundamentais, os quais, entretanto, só podem ser apreendidos de maneira aproximativa. O arquétipo em si é um fator psicóide que pertence, por assim dizer, à parte invisível e ultravioleta do aspecto psíquico (p.150). ${ }^{10}$

Dessa forma, entendemos que os arquétipos são irrepresentáveis, porém são passíveis de certas visualizações através das suas representações, ou seja, o que visualizamos são as imagens arquetípicas.

Assim, chegamos à conclusão de que, na obra de arte, estamos diante de símbolos coletivos, universais e arquetípicos, exprimindo-se através da psique individual do artista. Isso nos leva a abordar o ponto fundamental do pensamento de Jung - o processo de individuação cujo simbolismo arquetípico está em estreita relação com o fenômeno do mito.

O processo de crescimento psíquico em direção a uma personalidade mais rica e madura não depende da vontade; ele se desenvolve ao longo da vida do indivíduo de modo involuntário e natural, como se fosse guiado por um centro organizador; Jung chama de Self ( $\mathrm{Si}$-mesmo) esse centro constituído pela totalidade da psique.

10 A natureza da Psique, op. cit. 
E esse processo só se torna real, se o indivíduo dele tem consciência e vive em união com ele.

Para isso, é necessário trazermos os arquétipos para a linguagem da consciência, experienciá-los e conviver com eles de novo através das figuras, dos mitos, das imagens arquetípicas e símbolos arcaicos, que foram o motivo por que retomamos em sua busca. É como se o indivíduo tivesse que refazer o caminho de seus ancestrais, percorrendo o trajeto de volta à fonte, para ali, no entroncamento da estrada, orientar-se de novo.

O processo de individuação efetua-se por etapas, com certos símbolos arquetípicos, aparecendo como marcos, referências, variando naturalmente de acordo com cada elemento. Por isso é que o homem no seu processo de individuação, na sua busca instintiva e permanente de realizar plenamente suas potencialidades inatas, só consegue construir a sua existência como indivíduo quando é capaz de produzir algo que represente esse arquétipo, quando consegue transformar em algo legível aquilo que é ilegível para a sua época, conforme verificamos nessa fala de Jung:

O processo criativo consiste numa ativação inconsciente do arquétipo e numa elaboração e formalização da obra acabada. De certo modo a formação da imagem primordial é uma transcrição para a linguagem do presente pelo artista, dando possibilidade de encontrar o acesso às fontes mais profundas da vida que, de outro modo, lhe seria negado (1985, p.71).

Para Jung, o caráter social da obra reside em encontrar no inconsciente a imagem que esclareça ou que compense as frustrações e as carências do mundo contemporâneo do produtor. É uma leitura atualizada pelo artista dessa imagem primordial, que o criador extrai do inconsciente, aproxima-a do consciente, modifica-a e atualiza-a no discurso, concretizando na ou pela persona poética essas imagens ancestrais, de forma que elas sejam entendidas e lidas agora, no
mundo contemporâneo do autor.

Assim, justificam-se as convenções e posturas artísticas diferenciadas de poetas para poetas, dos gêneros literários e dos denominados estilos de época. Cada artista ou cada período organiza seu imaginário segundo suas próprias tendências, carência ou necessidade de época. Por exemplo, enquanto a Idade Média tende a 
favorecer a atitude mística e subjetiva do homem, o Renascimento orienta-se para a pesquisa de leis objetivas, valorizando os fatos e o pensamento racional. Assim como as tendências de época são reprogramadas de acordo com as necessidades dos indivíduos, assim também "as formas mitológicas" aguardam uma elaboração na fantasia criativa, esperando uma transcrição adequada e uma linguagem compreensível.

Desvendar, na palavra dita, na superfície do texto, as motivações inconscientes e mutáveis que são atualizadas nos discursos poéticos, quer nos movimentos literários - classicismo, barroco, romantismo, realismo, simbolismo, modernismo e outros -, quer no imaginário artístico, desde o passado mais remoto até o contemporâneo, é o que constitui, enfim, o diálogo profícuo entre a psicologia analítica e a crítica literária, mãos que se dão em busca de decifrar o mistério humano da criação.

Para Jung, esse percurso artístico diferenciado, mas, ao mesmo tempo, de base arquetípica comum "são tendências da arte que trazem à tona aquilo de que a respectiva atmosfera espiritual mais necessita" (p. 27).

Assim, os postulados teóricos da Psicologia Analítica de cujos aspectos podemos nos servir para a leitura do texto literário, assentamse no processo psíquico da criação artística; tal processo que, à semelhança do inconsciente, tem suas raízes nas imagens primordiais, traduz-se, perpetua e atualiza-se na simbologia do texto literário, na representação e configuração de imagens arquetípicas, fazendo do discurso literário um momento do ontem, do hoje e do amanhã, levando Jung a afirmar: "após o término da obra de arte, conseguiremos reconstruir o projeto primitivo da imagem primordial" (p. 69). 


\section{Referências bibliográficas}

BAKHTIN, Mikhail. Marxismo e filosofia da linguagem: Tradução Michel Lahud e Yara Frateschi Vieira. 6.ed. São Paulo: Hucitec, 1992. HAUPTMANN, Gerhart. Apud: JUNG, C. G. Relação da psicologia analítica com a obra de arte poética. In: $O$ espírito na arte e na ciência. Tradução Maria de Moraes Barros. Petrópolis: Vozes, 1985.

JUNG, C.G. A natureza da psique. Tradução Dom Matheus Ramalho Rocha. Petrópolis: Vozes, 1991.

JUNG, C.G. Psicologia do inconsciente. Tradução Maria Luiza Appy. Petrópolis: Vozes, 1987.

JUNG, C. G. Psicologia e poesia. In: O espírito na arte e na ciência. Tradução Dora Ferreira da Silva e Ruben Siqueira Bianchi. Petrópolis: Vozes, 1985.

JUNG, C. G. Relação da psicologia analítica com a obra de arte poética. In: O espírito na arte e na ciência. Tradução Maria de Moraes Barros. Petrópolis: Vozes, 1985.

KRISTEVA, Julia. Introdução à semanálise. Tradução Lúcia Helena França Ferraz. São Paulo: Perspectiva, 1974.

LEITE, Dante Moreira. Psicologia e literatura. São Paulo: Nacional, 1977.

SHARP, Daryl. Léxico junguiano: dicionário de termos e conceitos. Tradução Raul Milanez. São Paulo: Cultrix, 1997.

SILVEIRA, Nise da. O mundo das imagens. São Paulo: Ática, 1992. 